\title{
Evaluation of Extreme Hip Joint Movement after Total Hip Arthroplasty: A Retrospective Study
}

\author{
Iwan Budiwan Anwar ${ }^{1,2}$, Emile van der Heide ${ }^{2}$, J. Jamari ${ }^{3}$, Eko Saputra ${ }^{2,3}$, Asep Santoso $^{1 *}$, Denny Adriansyah ${ }^{1}$, Zarkasyi Arimukti $^{1}$
}

${ }^{1}$ Department of Orthopaedic and Traumatology, Universitas Sebelas Maret, Prof. Dr. R. Soeharso Orthopaedic Hospital, Surakarta, Indonesia; ${ }^{2}$ Laboratory for Surface Technology and Tribology, Faculty of Engineering Technology, University of Twente, Enschede, The Netherlands; ${ }^{3}$ Department of Mechanical Engineering, Laboratory for Engineering Design and Tribology, Universitas Diponegoro, Semarang, Indonesia

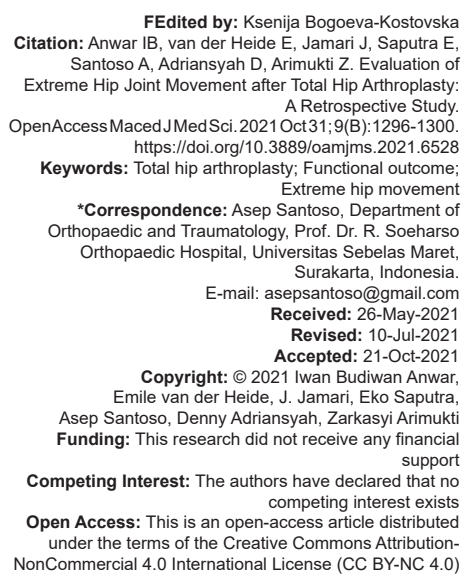

\section{Introduction}

Total hip arthroplasty (THA) reported as one of the most successful surgery in the field of orthopedic. The number of THA is increased every year in our country.

Mobility of the hip joint after THA is important to achieve. Subjects expect to perform daily activity, Including thus with extreme hip joint movement: squatting, Muslim prayers (Salat), and even sport activities.

Extreme movement describes as motion with a high risk of impingement that can lead to dislocation which becomes the main reason for clinical failures [1]. This common cause leads some orthopedic doctors educate subject not to perform an extreme movement. Meanwhile, people demand to be able to perform extreme movement are always questioned. Sugano et al. [2] through their study report that daily activity between Japanese-style and western-style are quite different.
Saputra et al. [3] found the impingement and dislocation have greater risk in picking up activities. Other studies by Yoshimine and Ginbayashi mention about factors that determine the range of motion (ROM) which a THA can achieve, four of these are associated with prosthetic component orientation: (1) Acetabular cup anteversion, (2) acetabular cup inclination, (3) femoral stem version and (4) femoral component neck axis away from the transverse plane which is dependent upon femoral stem varus-valgus within the femoral canal and femoral component neck-shaft angle [4].

There are various factors that may increase the risk of impingement or dislocation of THA prosthesis; except the subjects themselves, factors that we cannot choose. Performing activity without limited motion is inevitable for the patients even after the information after surgery. The number of studies discussed about subjects capability to perform a daily activity with extreme movement related to high risk of impingement and dislocation are still limited. The present study aimed to compare factors which may affect the ability 
of the patients receiving THA to perform an extreme hip joint movement in daily living.

\section{Methods}

This was a retrospective study to subjects from our institution who received total hip arthroplasty surgery from January 2019 to April 2020. Our study has been approved by ethic comission with letter number LB.02.02/XXX.3.1.2/6523/2020. The inclusion criteria were adults performed THA, no complication during and after the operation, primary THA, and no socioeconomic problem. This study focused on the analysis of the subjects ability to perform extreme hip joint motion daily. There were a total of 22 subjects during this period received THA. Evaluated factors Include age, gender, body mass index (BMI), socio-economic status, diagnosis, physical therapy, radiographic acetabular inclination, acetabular cup diameter, and head diameter. Clinical evaluation performed with Harris hip score. Extreme hip joint movement evaluation performed with patient's ability to perform squatting and Salat (prayer). We also compare the time needed (onset) to perform first-time extreme movement from the day of surgery. Patient's ability to perform extreme hip joint movement was categorized into two categories: Excellent group and modified group. Excellent outcome defined when subject able to perform an extreme hip movement (prostration, bowing, and sitting position) in salat activity. "Modified" outcome are those with limited movement and unable to perform a normal movement in Salat activity. All surgery was performed with the posteriorlateral approach in lateral decubitus position with the use of cementless prosthesis both on acetabular and femoral component. Post-operative rehabilitation includes early joint motion, muscle strengthening, and partial weight-bearing as pain tolerated. Full-weight bearing is allowed after 4 weeks. Radiographic examination obtain on several subjects in excellent group using Philips Digital-Diagnostic Value Room. Minimum of follow-up is 6 months. The chi-square and Mann-Whitney tests were used for data analysis.

\section{Results}

There was a total of 22 subjects included in this study with the age range 26-61 years old. We found 9 (40.9\%) male, and 13 (59.1\%) female. Comorbidities in subjects such as 100 diabetes mellitus and hypertension. Other comorbidities like stroke or neurologic disorder were excluded in this research. We found 11 subjects had excellent category in extreme hip joint movement and the rest of 11 subjects had modify in performing extreme hip joint movement. Subject characteristics showed in Table 1.

Table 1: Characteristic research subjects

\begin{tabular}{ll}
\hline Characteristic & Result $(\mathrm{n}=22)$ \\
\hline Gender & \\
Male & $9(40.9 \%)$ \\
Female & $13(59.1 \%)$ \\
Age & $48.09 \pm 12.92$ \\
BMI & $23.93 \pm 3.40$ \\
Comorbidity & $18(81.8 \%)$ \\
$\quad$ None & $4(18.2 \%)$ \\
Present & \\
Trauma History & $9(40.9 \%)$ \\
None & $13(59.1 \%)$ \\
Yes & $10(45.5 \%)$ \\
Diagnosis & $8(36.4 \%)$ \\
$\quad$ Primary & $4(18.2 \%)$ \\
Secondary & \\
Other & \\
\hline
\end{tabular}

The data showed that the mean age of subject with excellent mobility is $47.64 \pm 9.45$ and $48.55 \pm$ 16.15 in modified group. BMI also gives a lower value by $22.84 \pm 2.67$ in excellent mobility group compared to $25.01 \pm 3.81$ in the modified patients (Table 2). The median size of acetabulum had been used in excellent group shows larger size compared to modified group (Table 3). No significant different on femoral head and acetabulum diameter between the two groups. Radiologic evaluation in extreme position (prostration, bowing, sitting position, and squatting) performed on a subject with excellent group. Possible impingement site can be revealed through radiology evaluation as seen in Figure 1. Radiographic examination obtained from excellent subjects in Figures 2 and 3.

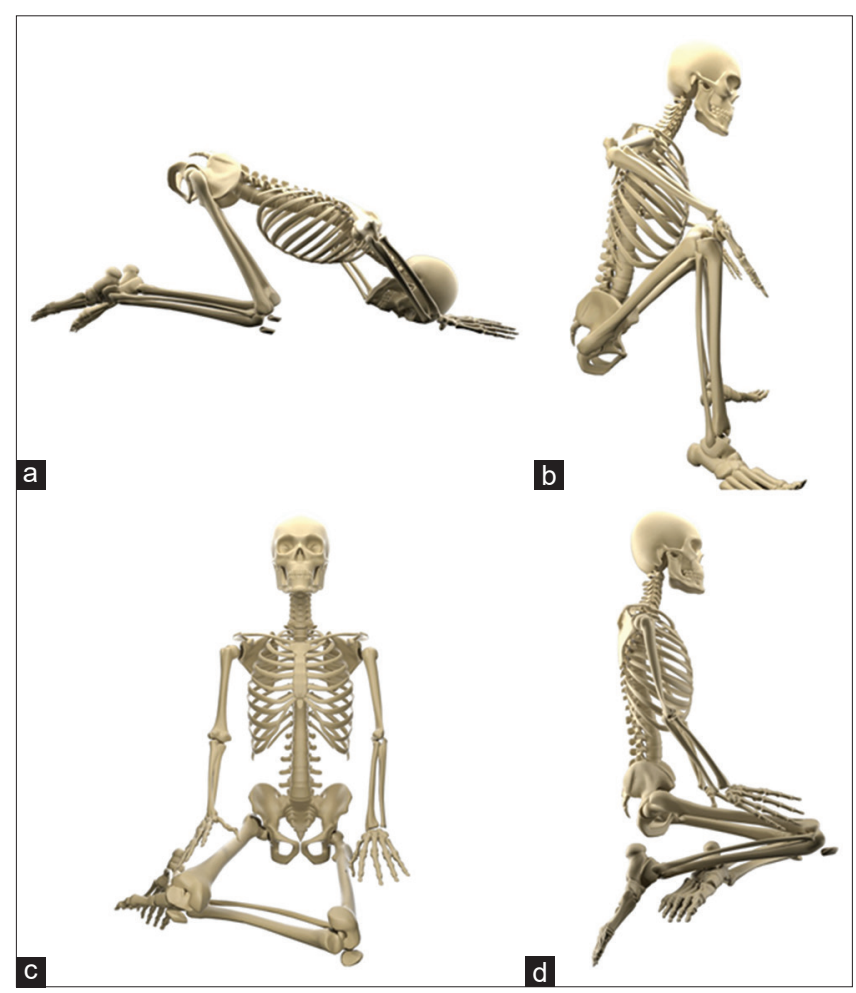

Figure 1: Illustration of skeleton in several extreme hip joint movements. (a) Prostration, (b) Squatting, (c) Sitting (anterior view), (d) Sitting (lateral view) 


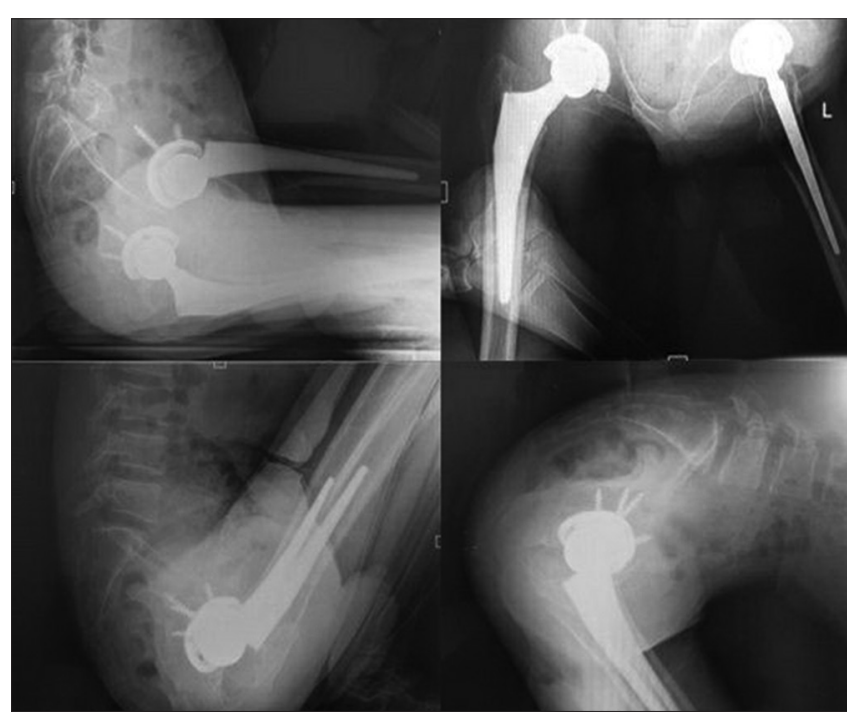

Figure 2: Radiograph of patients with bilateral THA performing extreme positions in Salat activity

\section{Discussion}

This study focused on identifying factors which may affect the ability of a patient to perform an extreme hip movement after THA. We found gender is not related to functional outcomes after THA (p-value: 0.665 ). Age also not significantly related to outcomes in extreme movement after THA. Subject and $48.55 \pm 16.15$ for in modified group. In contrast with a study by Vincent et al., they stated either age

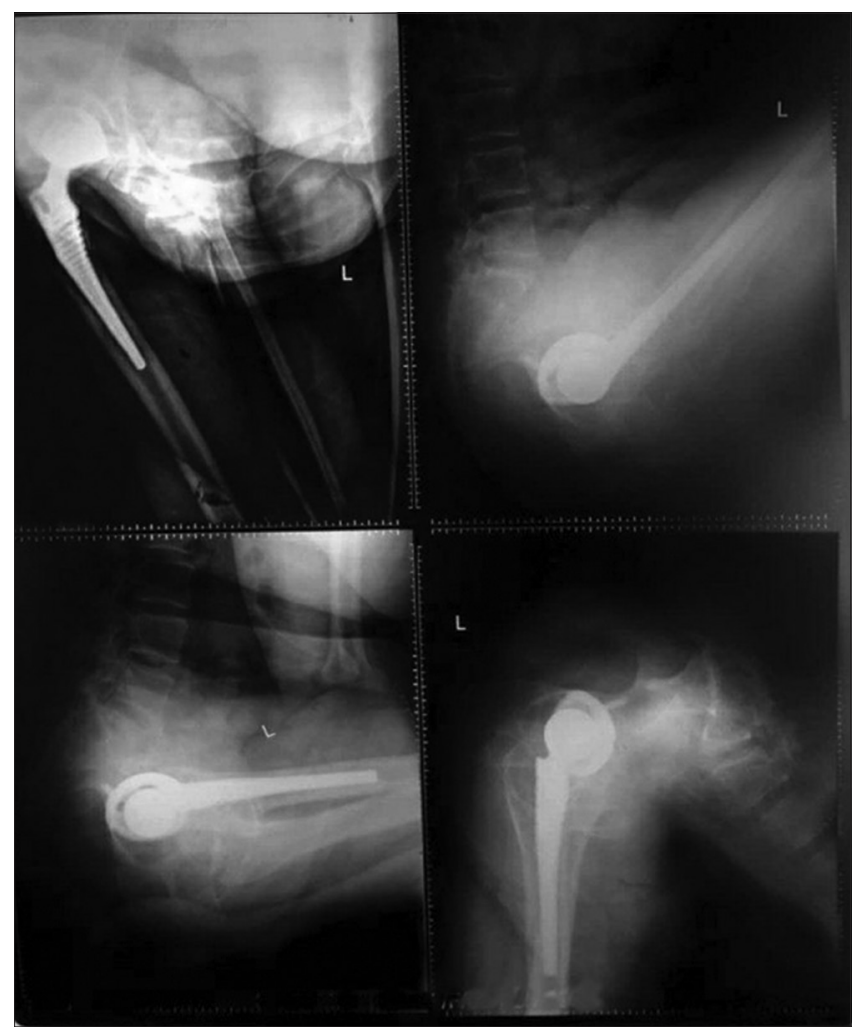

Figure 3: Radiograph of patients with unilateral THA performing extreme positions in Salat activity with excellent mobility has mean age $47.64 \pm 9.45$

or sex was a significant main effect for functional outcome after THA. Their study showed that woman and subject older than 85-year-old provide longer hospitalization while younger subject gives early discharge from hospital [5]. A meta-analysis by Buirs et al. found about age related to functional outcome, $60 \%$ of studies report a significant negative association. In correlation with gender differences, provide inconsistent evidence with functional outcome after THA [6].

Table 2: Characteristic subjects of excellent 236 and modified group

\begin{tabular}{|c|c|c|c|c|}
\hline Gender $^{a}$ & & & $X 2=0.188$ & 0.665 \\
\hline Male & $5(45.5 \%)$ & $4(36.4 \%)$ & & \\
\hline Female & $6(54.5 \%)$ & $7(63.6 \%)$ & & \\
\hline $\mathrm{Age}^{\mathrm{c}}$ & $47.64 \pm 9.45$ & $48.55 \pm 16.15$ & $\mathrm{t}=-0.161$ & 0.874 \\
\hline$B M l^{\circ}$ & $22.84 \pm 2.67$ & $25.01 \pm 3.81$ & $t=-1.542$ & 0.139 \\
\hline Comorbidity $^{\mathrm{a}}$ & & & $X 2=0.000$ & 1.000 \\
\hline Present & $9(81.8 \%)$ & $9(81.8 \%)$ & & \\
\hline None & $2(18.2 \%)$ & $2(18.2 \%)$ & & \\
\hline Trauma history ${ }^{\mathrm{a}}$ & & & $X 2=0.188$ & 0.665 \\
\hline None & $4(36.4 \%)$ & $5(45.5 \%)$ & & \\
\hline Yes & $7(63.6 \%)$ & $6(54.5 \%)$ & & \\
\hline Diagnosis $^{\mathrm{b}}$ & & & $Z=-0.426$ & 0.670 \\
\hline Primary & $5(45.5 \%)$ & $5(45.5 \%)$ & & \\
\hline Secondary & $5(45.5 \%)$ & $3(27.3 \%)$ & & \\
\hline Other & $1(9.1 \%)$ & $3(27.3 \%)$ & & \\
\hline
\end{tabular}
${ }^{a}$ Nominal categorical data tested by Chi-square test: frequency (\%), ${ }^{b}$ Ordinal categorical data were tested by Mann Whitney test: frequency (\%), cnormally distributed numerical data were tested by t-test: mean \pm sd.

The study by Hakim et al. showed that functional outcomes in correlation with BMI of subjects which shows no different between subject with or without overweight status [7]. This result is in line with our findings. Although the results of our recent study showed that the majority of subject in excellent group has smaller BMI, while higher BMI was found in modified group ( $p$-value: 0.874 ). However, study by Polat et al. showed that most of patient underwent THA have increasing of BMI due to immobilization. Those with higher BMI after operation give smaller functional outcomes compare to subject with no increase of BMI [8]. Therefore, the correlation or effect of obesity in clinical and functional outcomes after THA still controversial.

Comorbidities present in both group, modified and excellent outcomes have a similar prevalence of comorbidities. Our finding is in accordance with metaanalysis from Buir et al. which included 13 studies about comorbidities in relation to functional outcomes. There were 11 studies showed no effect of comorbidities to functional outcome. These provide strong evidence

Table 3: Comparison between size of acetabulum, head and time to perform extreme movement on subject with excellent and modified outcomes

\begin{tabular}{|c|c|c|c|c|}
\hline \multirow[t]{2}{*}{ Variable } & \multicolumn{2}{|l|}{ Group } & \multirow[t]{2}{*}{ Statistic } & \multirow[t]{2}{*}{$p$-value } \\
\hline & Excellent $(n=11)$ & Modified $(n=11)$ & & \\
\hline \multicolumn{5}{|l|}{ Acetabulum size } \\
\hline $44-46$ & $3(42.9 \%)$ & $4(57.1 \%)$ & $Z=-1.764$ & 0.078 \\
\hline $48-50$ & $5(62.5 \%)$ & $3(37.5 \%)$ & $Z=-2.049$ & $0.040^{*}$ \\
\hline $52-56$ & $3(42.9 \%)$ & $4(57.1 \%)$ & $Z=-0.935$ & 0.350 \\
\hline \multicolumn{5}{|l|}{ Head size } \\
\hline 24 & $1(100.0 \%)$ & $0(0.0 \%)$ & - & - \\
\hline 28 & 7 (46.7\%) & $8(53.3 \%)$ & $Z=0.000$ & 1.000 \\
\hline 32 & $3(50.0 \%)$ & $3(50.0 \%)$ & $\bar{Z}=0.000$ & 1.000 \\
\hline $\begin{array}{l}\text { Onset of extreme hip } \\
\text { movement (month) }\end{array}$ & $3(2-6)$ & $3(2-9)$ & $Z=-1.413$ & 0.158 \\
\hline
\end{tabular}


of a negative correlation between comorbidities and functional outcomes [6].

Probably the optimal cup size for Indonesia people is 48-50. The usage of a bigger size of cup acetabulum gives significance result for a subject with excellent outcomes. The previous finding, Kelley et al found that acetabular diameter $(>56 \mathrm{~mm}$ ) have significant risk of dislocation compare to a smaller size (<54 mm) [9], Peter et al. also support this hypotized through their finding, subject with cup diameter $>56 \mathrm{~mm}$ provide 2 times risk of dislocation [10]. Our results provide no significance results between all groups. Study by Smoesh et al. stated dislocation rate decreased significantly as the size of the head increased in primary THA [11]. Another study showed that larger heads (22$32 \mathrm{~mm}$ ) have not been proved to be clinically superior with regard to dislocation in the primary THA setting [12] and smaller head tends to have optimal wear but more likely to dislocate [13].

There were no significance differences in age, gender, BMI, comorbidities, and implant size. Most of the study provide the position of the implant might have the most crucial factors influencing joint motion after THA. Impingement results when two non-articular surfaces come into contact during a joint ROM that might lead to dislocation. According to Glen et al. in his study stated the healthy normal benchmark for hip flexion is $120^{\circ}$ with an additional $5-10^{\circ}$ concluded as soft tissue impingement [14]. Zhou et al. examine the mean flexion angle in the subject who underwent THR, which is $121.3^{\circ}$ [15]. According to our measurement in the excellent group, the average hip flexion is $131^{\circ}$. High flexion angle results to impingement of implant and might lead to the durability of an implant. Further study about extreme movement after THA and its durability is needed.

This study has some limitations include small number of subjects. Radiographic also evaluation could not be performed to all subjects, hence did not include in the analysis.

Evaluation of extreme movement more focused only on movement in Salat activity (Muslim prayer), therefore, subject who has to different religion was excluded in this study.

\section{Conclusion}

Subject receiving THA can be expected to perform extreme hip joint movement post-operatively. Age, gender, BMI, and comorbidities seem to be had no effect on the patient's ability to perform extreme hip movement post-operatively.

\section{References}

1. Brown TD, Elkins JM, Pedersen DR, Callaghan JJ. Impingement and dislocation in total hip arthroplasty: Mechanisms and consequences. lowa Orthop J. 2014;34:1-15. PMid:25328453

2. Sugano N, Tsuda K, Miki H, Takao M, Suzuki N, Nakamura N. Dynamic measurements of hip movement in deep bending activities after total hip arthroplasty using a 4-dimensional motion analysis system. J Arthroplasty. 2012;27(8):1562-8. https://doi.org/10.1016/j.arth.2012.01.029 PMid:22459125

3. Saputra E, Anwar IB, Jamari J Finite element analysis of artificial hip joint movement during human activities. Proc Eng. 2013;68:102-8. http://doi.org/10.1016/j.proeng.2013.12.154

4. Yoshimine F, Ginbayashi K. A mathematical formula to calculate the theoretical range of motion for total hip replacement. J Biomech. 2002;35(7):989-93. https://doi.org/10.1016/ s0021-9290(02)00040-4

5. Vincent HK, Alfano AP, Lee L, Vincent KR. Sex and age effects on outcomes of total hip arthroplasty after inpatient rehabilitation. Arch Phys Med Rehabil. 2006;87(4):461-7. https://doi.org/10.1016/j.apmr.2006.01.002

PMid:16571383

6. Buirs LD, Van Beers LW, Scholtes VA, Pastoors T, Sprague S, Poolman RW. Predictors of physical functioning after total hip arthroplasty:Asystematic review. BMJ Open. 2016;6(9):e010725. https://doi.org/10.1136/bmjopen-2015-010725

PMid:27601486

7. Hakim Z, Rutherford C, Mckiernan E, Helm T. Outcome in patients with high body mass index following primary total hip arthroplasty. Adv Orthop Surg. 2015;2015:1-4. https://doi. org/10.1155/2015/758486

8. Polat G, Ceylan HH, Sayar S, Kucukdurmaz F, Erdil M, Tuncay I. Effect of body mass index on functional outcomes following arthroplasty procedures. World J Orthop. 2015;6(11):991-5. https://doi.org/10.5312/wjo.v6.i11.991

PMid:26716096

9. Kelley SS, Lachiewicz PF, Hickman JM, Paterno SM Relationship of femoral head and acetabular size to the prevalence of dislocation. Clin Orthop Relat Res. 1998;355:16370. https://doi.org/10.1097/00003086-199810000-00017 PMid:9917601

10. Peter R, Lübbeke A, Stern R, Hoffmeyer P. Cup size and risk of dislocation after primary total hip arthroplasty. J Arthroplasty. 2011;26(8):1305-9. https://doi.org/10.1016/j.arth.2010.11.015 PMid:21414747

11. Singh SP, Bhalodiya HP. Head size and dislocation rate in primary total hip arthroplasty. Indian J Orthop. 2013;47(5):443-8. https://doi.org/10.4103/0019-5413.118198 PMid:24133302

12. Soong M, Rubash HE, Macaulay W. Dislocation after tota hip arthroplasty. J Am Acad Orthop Surg. 2004;12(5):314-21. https://doi.org/10.5435/00124635-200409000-00006 PMid:15469226

13. Zahar A, Rastogi A, Kendoff D. Dislocation after total hip arthroplasty. Curr Rev Musculoskelet Med. 2013;6(4):350-6. https://doi.org/10.1007/s12178-013-9187-6 PMid:24170479

14. Turley GA, Williams MA, Wellings RM, Griffin DR. Evaluation of range of motion restriction within the hip joint. Med Biol Eng Comput. 2013;51(4):467-77. https://doi.org/10.1007/ s11517-012-1016-3 
PMid:23263850

15. Zhou H, Wang CT, Ji WT, Zeng $X$ Sen, Fang $S$, et al. Motion performance and impingement risk of total hip arthroplasty with a simulation module. J Zhejiang Univ Sci B. 2013;14(9):849-54. https://doi.org/10.1631/jzus.b1200168

PMid:24009206 